\title{
Modified Multi Input Multilevel DC-DC Boost Converter for Hybrid Energy Systems
}

\author{
Ram Prakash Ponraj, Devadharshini Ganeshprabhu, Haripriya Balaji, Hemadharshini Ganesan, \\ Keerthana Dhanabalan
}

\begin{abstract}
DC-DC converters are playing an important role in designing of Electric Vehicles, integration of solar cells and other DC applications. Contemporary high power applications use multilevel converters that have multi stage outputs for integrating low voltage sources. Conventional DC-DC converters use single source and have complex structure while using for Hybrid Energy Systems. This paper proposes a multi-input, multi-output DC-DC converter to produce constant output voltage at different input voltage conditions. This topology is best suitable for hybrid power systems where the output voltage is variable due to environmental conditions. It reduces the requirement of magnetic components in the circuit and also reduces the switching losses. The proposed topology has two parts namely multi-input boost converter and level-balancing circuit. Boost converter increases the input voltage and Level Balancing Circuit produce Multi output. Equal values of capacitors are used in Level Balancing Circuit to ensure the constant output voltage at all output stages. The operating modes of each part are given and the design parameters of each part are calculated. Performance of the proposed topology is verified using MATLAB/Simulink simulation which shows the correctness of the analytical approach. Hardware is also presented to evaluate the simulation results.
\end{abstract}

Keywords : DC-DC converter, Multi input Multi output (MIMO), PWM technique, wide-input range, level-balancing, hybrid energy systems.

\section{INTRODUCTION}

\section{A} vailability of fossil fuels depleted and the price increases over the years. Increasing demand thrive the studies on alternate energy sources. Renewable energy sources are found to be the right alternate for the fossil fuels and available

Revised Manuscript Received on April 12, 2020.

* Correspondence Author

Ram Prakash Ponraj*, is currently working as Assistant Professor in Department of Electrical and Electronics Engineering in Saranathan College of Engineering, Tiruchirapalli, India. PH-+919487676423. E-mail: gprsahara@gmail.com

Devadharshini Ganeshprabhu, is currently pursuing her Bachelor degree in Electrical and Electronics Engineering in Saranathan College of Engineering, Tiruchirapalli, India.

Haripriya Balaji, is currently pursuing her Bachelor degree in Electrical and Electronics Engineering in Saranathan College of Engineering, Tiruchirapalli, India.

Hemadharshini Ganesan, is currently pursuing her Bachelor degree in Electrical and Electronics Engineering in Saranathan College of Engineering, Tiruchirapalli, India.

Keerthana Dhanabalan, is currently pursuing her Bachelor degree in Electrical and Electronics Engineering in Saranathan College of Engineering, Tiruchirapalli, India.

(C) The Authors. Published by Blue Eyes Intelligence Engineering and Sciences Publication (BEIESP). This is an open access article under the CC BY-NC-ND license (http://creativecommons.org/licenses/by-nc-nd/4.0/) abundant in nature. New methodologies have been introduced over the past years to increase the stake of the renewable energy sources and also to meet the increasing power demand. Inverters and Converters were widely used however choppers had less attention in power conversion in spite of used virtually in all power conversion processes [1]. At the present time, due to Electric Vehicles and of various advantages like low harmonics and low EMI DC-dc converters are gathering attention and the use of DC-DC converters are burgeoning [2].

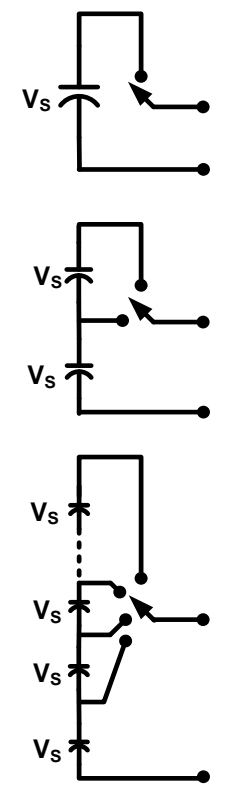

Fig.1. Basic DC-DC conversion system

Choppers also use less magnetic components that decrease the complexity of the circuit and overall manufacturing cost [3]. But the DC-DC converters have more voltage balancing problems compared to converters and inverters [4]. Most of the renewable energy sources are not being used throughout the year and their utilization is limited. By using multiple sources; normally renewable energy sources, hybrid power systems increase the reliability and utilization of renewable energy sources [5].

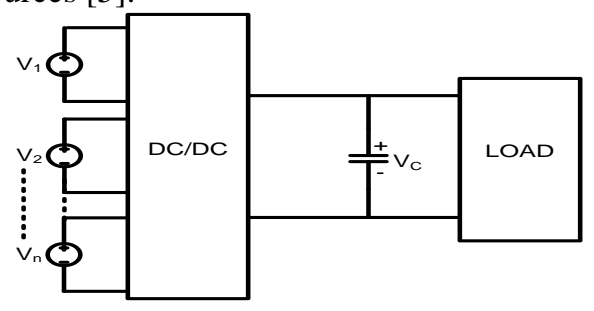

Fig.2. DC-DC converter system with multiple sources

Published By:

Blue Eyes Intelligence Engineering \& Sciences Publication 
Contemporary applications like Electric Vehicle also require multiple DC voltages and uses Multiple Input and Multiple Output (MIMO) choppers [6]. Basic multiple input DC converter structure is given in Fig.1 and Fig.2.In these structures, output voltage is the sum of all input voltages [7]. These type of converters used in Distributed generations and high voltage applications due to their simple structure, less volume, less switches and magnetic components [8]. These converters are categorized in to three major categories such as magnetic, Electrical and Electromagnetic type [9]. Earlier days the inputs are connected in parallel to develop a multi-input DC-DC converter. Modern topologies use many configurations to create multiple inputs [10,11].These topologies use high energy rating capacitors to reduce stress on components and inductor, ripple in the input current and to achieve high effective switching frequency [12,13]. To reduce the effect of capacitors and inductors in increasing the input and output voltages, many inputs are connected in series through semiconductor switches. Output voltage of these converters is the sum of input voltages and these converter reduce the effect of magnetic components in the circuit also $[14,15]$. The important contemporary applications of these converters are Electric Vehicle for torque ripple reduction [16,17] and Multi-level Inverter circuits [18]. From the manuscripts cited above, this article proposes a novel DC-DC converter topology with multiple inputs and multiple outputs. A General structure of the proposed topology also presented. Performance of the converter is verified using simulation and Hardware implementation.

\section{BASIC MODULES}

The Basic module of Multi-input DC converter is presented in Fig.2. It uses " $n$ " number of sources in which each source connected in series with a switch. If the switch is ' $\mathrm{ON}$ ' then the sources is connected with the circuit. If the switch is 'OFF' then the source is not connected in the circuit and bypassed using a diode connected in parallel.

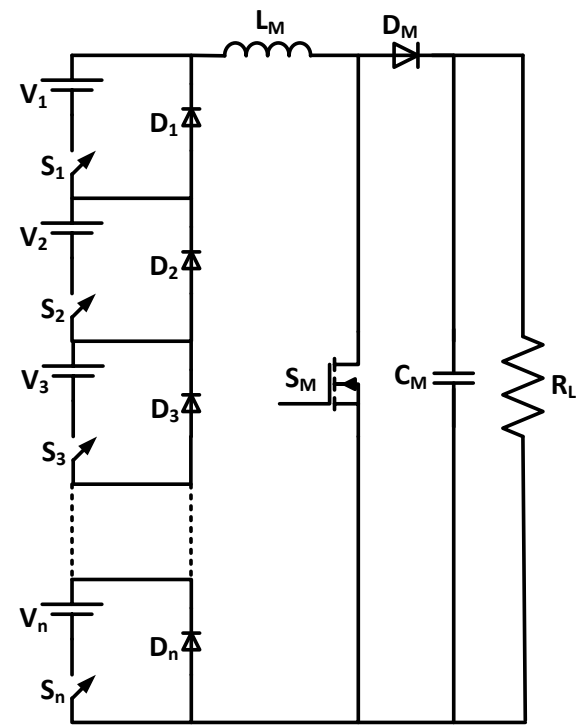

Fig.3.General structure of Multi input DC-DC Converter System

The double input structure derived from Fig.3, is given in Fig.4. It uses two sources connected in series with the switches. Each module is connected with a bypass diode to bypass the current when the source is not connected. The inputs are connected with a normal boost converter comprising of an Inductor $\mathrm{L}_{\mathrm{M}}$, Switch $\mathrm{S}_{\mathrm{M}}$ and capacitor $\mathrm{C}_{\mathrm{M}}$. Entire setup is connected with a load $R_{L}$.

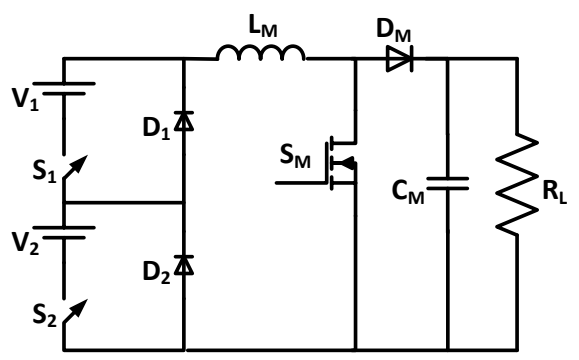

Fig.4 Double input boost converter topology
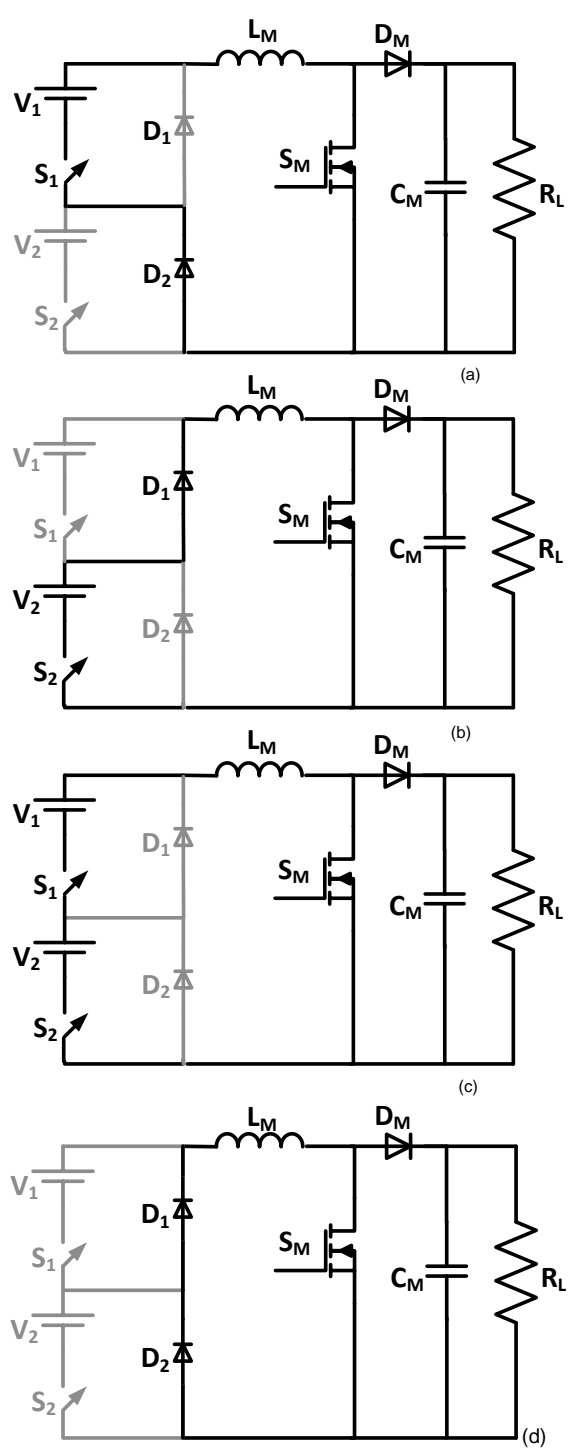

Fig.5. operation of boost converter when a) $S_{1} O N$ b) $S_{2}$ ON c) both $S_{1}$ and $S_{2} O N$ d) Both inputs are OFF

Fig.5.a shows the operation of the topology when $V_{1}$ alone is supplying power to the Load. The load voltage is described by the switching angle of $S_{M}$ and input $V_{1}$ alone. $V_{2}$ is in OFF condition and it is bypassed through the diode $\mathrm{D}_{2}$.

Fig.5.b shows the operation of the topology when $V_{2}$ alone is supplying power to the Load. The load voltage is described by the switching angle of $S_{M}$ and input $V_{2}$ alone. $V_{1}$ is in OFF condition and it is bypassed through the diode $\mathrm{D}_{1}$.

Published By:

Blue Eyes Intelligence Engineering \& Sciences Publication

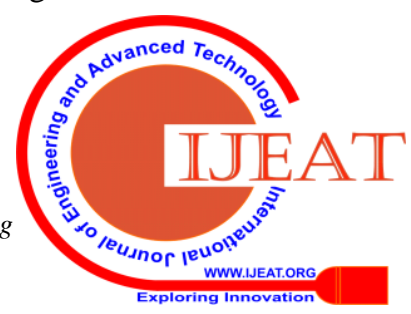


Fig.5.c shows the operation of the topology when both $V_{1}$ and $\mathrm{V}_{2}$ are supplying power to the Load. Now the load voltage is described by the switching angle of $S_{M}$ and sum of inputs $\mathrm{V}_{1}$ and $\mathrm{V}_{2}$. No bypass diodes are conducting at this mode.

Fig.5.d shows the operation of the topology when both inputs are OFF. Now, Inductor $\mathrm{L}_{\mathrm{M}}$ starts discharging through the load $\mathrm{R}_{\mathrm{L}}$ or through the Switch $\mathrm{S}_{\mathrm{M}}$ and the loop closed through the bypass diodes $\mathrm{D}_{1}$ and $\mathrm{D}_{2}$.

\section{A. Design of Basic Module}

The duty cycle of the boost converter used in the system is calculated for the output voltage $V_{O}$ and the maximum input voltage of $n * V_{S}$ as,

Duty cycle $\mathrm{D}=1-\frac{n \cdot V_{S}}{V_{o}}$
Output Voltage $V_{o}=\frac{n \cdot V_{S}}{(1-D)}$

Where $\mathrm{n}$ is the number of input sources. The minimum value of inductance $\mathrm{L}_{\mathrm{LOW}}$ and Capacitance $\mathrm{C}_{\mathrm{LOW}}$ are,

$$
\begin{aligned}
L_{\text {Low }} & =\frac{D(1-D)^{2} R_{L}}{2 f} \\
C_{\text {Low }} & =\frac{D}{R_{L} * A_{r} * f}
\end{aligned}
$$

The ripple voltage with respect to the output voltage is taken as,

$$
A_{\text {ripple }}=\left(\Delta V_{o} / V_{o}\right)
$$

The determined value of load current and the change in load current value is given by,

$$
\begin{aligned}
& I_{L, \text { high }}=\frac{n \cdot V_{S}}{(1-D) R_{L}} \\
& \frac{\Delta I_{L}}{2}=\frac{V_{S} D T}{2 L_{M}}
\end{aligned}
$$

Where, $\mathrm{V}_{\mathrm{S}}$ - source voltage, $\mathrm{f}$ - switching frequency and $\mathrm{R}_{\mathrm{L}}-$ Load impedance. Ripple Voltage $\mathrm{A}_{\text {ripple }}$ is considered as $0.5 \%$ of the output voltage

\section{PROPOSED CONVERTER MODULE}

The proposed DC converter is shown in Fig.6. It consists of a multi input boost converter and a level balancing circuit. Multi input boost converter was already discussed in previous chapter. The level balancing circuit consists of two diodes $\mathrm{D}_{1}, \mathrm{D}_{2}$, a voltage balancing capacitor $\mathrm{C}_{\mathrm{A}}$ and a voltage level shifting capacitor $\mathrm{C}_{1}$.

The overall load of the proposed network includes the resistance of Load $R_{L}$, Internal Resistance of each switch $R_{S W}$ and the internal Resistance of each diode $\mathrm{R}_{\text {diode }}$ at forward bias condiotion.

$R_{L, \max }=R_{L}+2 * R_{S W}+3 * R_{\text {diode }}$

Since the internal resistance of the switches and diode is negligible, then (8) would be restated as

$R_{L, \max }=R_{L}$

The Voltage across each capacitor is equal to the input voltage $\mathrm{V}_{\mathrm{DC}}$. So the overall output voltage across the capacitor $\mathrm{C}_{\mathrm{M}}$ is,

$$
V_{o 1}=\frac{2 V_{S}}{(1-D)}
$$

Since the input voltage of the self-balancing circuit is the output of the boost converter, then the output voltage of the level-balancing circuit is,

$$
V_{o 2}=V_{C 1}=2 * V_{01}=\frac{4 V_{S}}{(1-D)}
$$

The load current $I_{L}$ is calculated for the proposed inverter from (2) - (6) and is given by,

$$
I_{L, h i g h}=\frac{4 . V_{S}}{(1-D) R_{L}}
$$

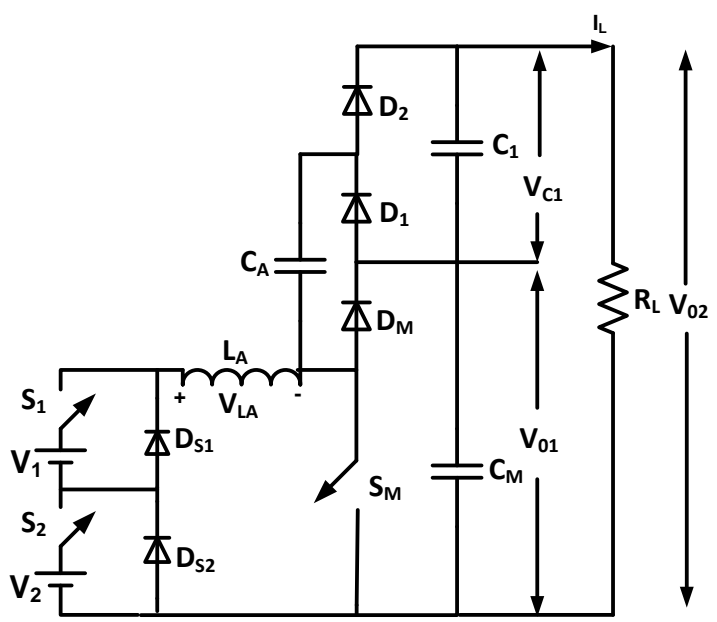

\section{MULTI INPUT BOOST LEVEL BALANCING CONVERTER CIRCUIT}

Fig.6. Proposed DC/DC Boost Multi-level Converter circuit

Various operating modes of proposed DC-DC converter is given in Fig.7. It shows the output and input voltages at various conditions. It also shows the output current and inductor current at various time periods.

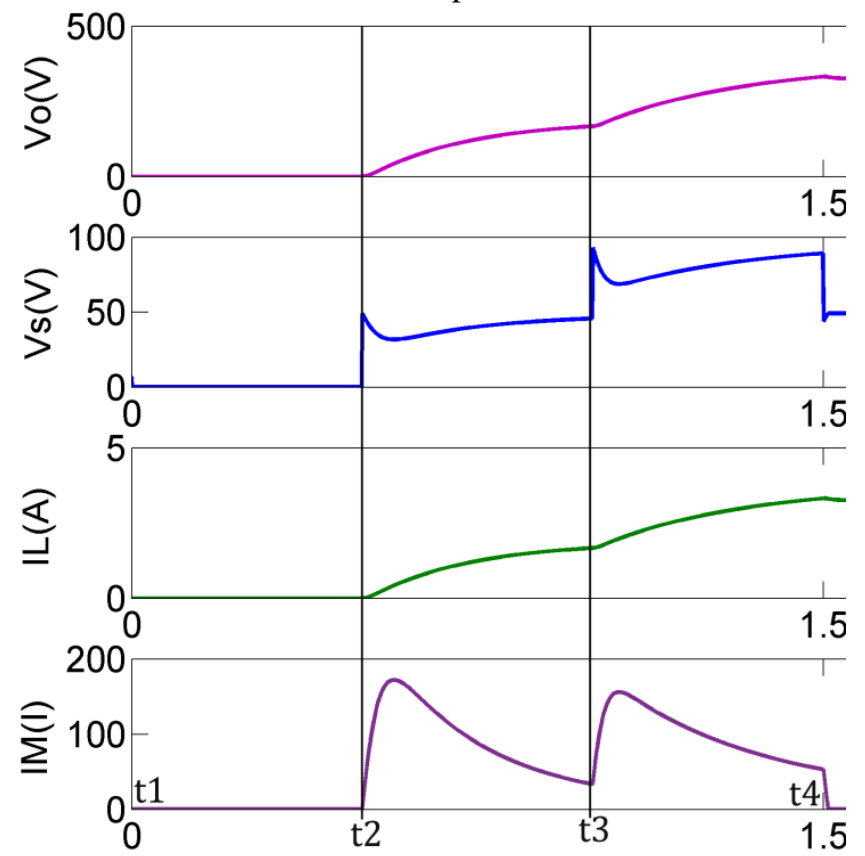

Fig.7. Circuit parameters at various operating modes

At operating mode 1 (t1- t2): Both inputs are OFF which is shown in Fig.8(a). The magnetic components are discharging through the diodes $D_{S 1}$ and $D_{S 2}$. The input voltage is $V_{S}=0$ and the output of boost converter is also zero. Take the inductor is charged at a value of $\mathrm{I}_{\mathrm{M} 1}$.

At operating mode 2 (t2- t3): Shown if Fig.8(b) at which any of the two inputs $V_{1}$ and $V_{2}$ is $O N$ and the input voltage is $\mathrm{V}_{\mathrm{S}}=\mathrm{V}_{1}$ or $\mathrm{V}_{2}$. Output voltage of the boost converter is described from (10) and is given by,

$$
V_{o 1}=\frac{V_{S}}{(1-D)}
$$

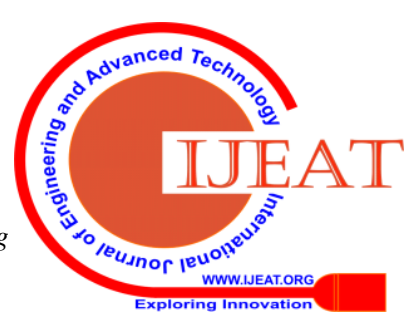


Capacitors $\mathrm{C}_{1}$ and $\mathrm{C}_{2}$ start charging and the output voltage start increasing. Inductor also starts charging, take initial value of inductor current as $\mathrm{I}_{\mathrm{M} 1}$ and the new value of inductor current $\mathrm{I}_{\mathrm{M} 2}$ at time $\mathrm{t} 3$ is,

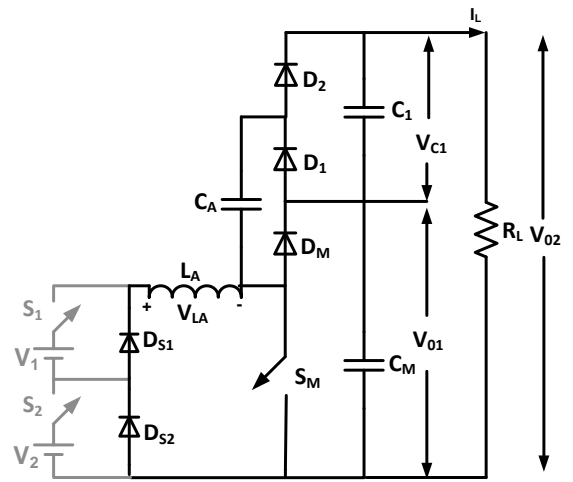

Fig.8(a) Operating mode-1 of proposed topology

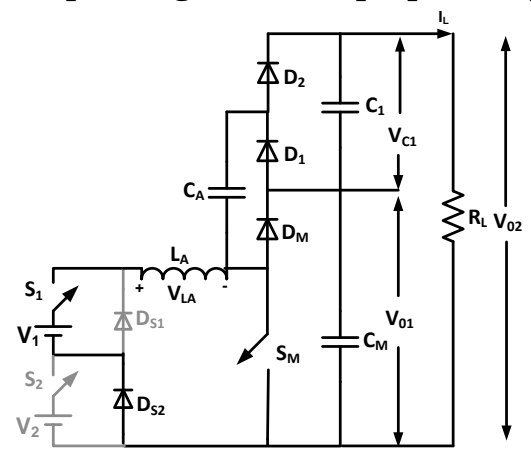

Fig.8(b) Operating mode-2 of proposed topology

$I_{M 2}=I_{M 1}+\frac{1}{L} \int_{t 2}^{t 3} V_{L A} d t=I_{M 2}+\frac{1}{L} V_{L A}(t 3-t 2)$

Since $\mathrm{V}_{\mathrm{LA}}=\mathrm{V}_{\mathrm{S}}=\mathrm{V}_{1}=\mathrm{V}_{2}$,

$I_{M 2}=I_{M 1}+\frac{V_{S}}{L}(t 3-t 2)=I_{M 1}+\frac{V_{1}}{L}(t 3-t 2)$

At operating mode $3(\mathrm{t} 3-\mathrm{t} 4)$ : Both inputs are $\mathrm{ON}$ and the input voltage is $2 \mathrm{~V}_{\mathrm{S}}=\mathrm{V}_{1}+\mathrm{V}_{2}$ and the topology at this operating mode is shown in Fig.8(c). Output of boost converter is described the duty cycle of the Switch $S_{M}$ and the value is given by (10). Take initial value of inductor current as $\mathrm{I}_{\mathrm{M} 1}$ and the new value of inductor current $\mathrm{I}_{\mathrm{M} 2}$ at time $\mathrm{t} 2$ is,

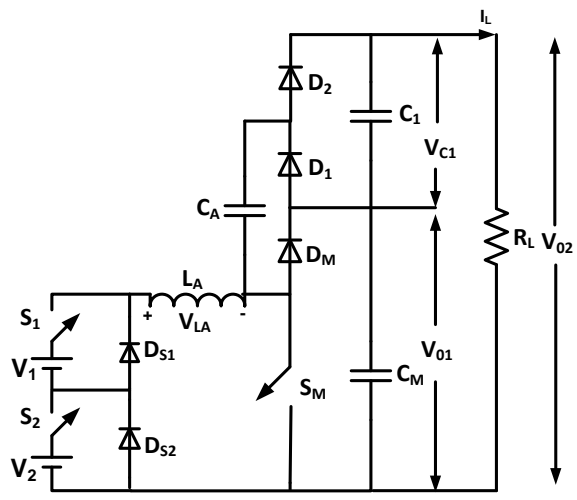

Fig.8(c) Operating mode-3 of proposed topology

$$
I_{M 3}=I_{M 2}+\frac{1}{L} \int_{t 3}^{t 4} V_{L A} d t=I_{M 2}+\frac{1}{L} V_{L A}(t 4-t 3)
$$

Since $\mathrm{V}_{\mathrm{LA}}=\mathrm{V}_{1}+\mathrm{V}_{2}=2 \mathrm{~V}_{\mathrm{S}}$,

$$
I_{M 3}=I_{M 2}+\frac{V_{S}}{L}(t 4-t 3)=I_{M 2}+\frac{2 V_{S}}{L}(t 4-t 3)
$$

Overall output voltage across load $\mathrm{R}_{\mathrm{L}}$ is given by (11) and the load current is given by (12).
By comparing multiple input multiple output (MIMO) topologies presented in [19-21] and [15], it states that proposed topology requires less number of magnetic components and switches. Table 1 summarizes the comparison of proposed topology and conventional topologies in view of inductor and switch requirement.

Table.1. comparison of topologies with component requirement

\begin{tabular}{|c|c|c|c|}
\hline $\begin{array}{c}\text { Proposed } \\
\text { topology }\end{array}$ & $\mathbf{N}_{\text {DC SOURCES }}$ & $\mathbf{N}_{\text {INDUCTORS }}$ & $\mathbf{N}_{\text {SWITCHES }}$ \\
\hline $\begin{array}{c}\text { Topology in } \\
\text { [19] }\end{array}$ & $\mathrm{n}$ & 1 & $\mathrm{n}+1$ \\
\hline $\begin{array}{c}\text { Topology in } \\
\text { [20] }\end{array}$ & $\mathrm{m}$ & 1 & $\mathrm{~m}$ \\
\hline $\begin{array}{c}\text { Topology in } \\
\text { [21] }\end{array}$ & $\mathrm{m}$ & $\mathrm{m}$ & $\mathrm{n}+\mathrm{m}$ \\
\hline $\begin{array}{c}\text { Topology in } \\
\text { [15] }\end{array}$ & $\mathrm{n}$ & 1 & $\mathrm{n}+1$ \\
\hline
\end{tabular}

Topology [21] requires ' $\mathrm{m}$ ' number of inductors for multi-stage output which increases complexity of the circuit. Proposed topology requires less number of switches compared to [19] and [20]. This decreases cost, volume and deriver requirement. Topology [15] requires same number of components but it requires asymmetric input voltages to get multi-stage output.

\section{SIMULATION AND HARDWARE RESULTS}

Performance of the proposed topology is evaluated with the Simulation and Hardware. Simulation has been carried out using Matlab/Simulink R2014a and the results are presented in Fig.9. Simulation was carried out for an input voltage of $50 \mathrm{~V}$. The load values of $50 \Omega$ and $25 \Omega$ are considered for full load and half load conditions respectively. The inductor value has been chosen as $8 \mathrm{mH}$ and the capacitor values at both the stages are made equal at a value of $89 \mu \mathrm{F}$. Switching frequency of $10 \mathrm{kHz}$ is chosen for the switch $\mathrm{S}_{\mathrm{M}}$.

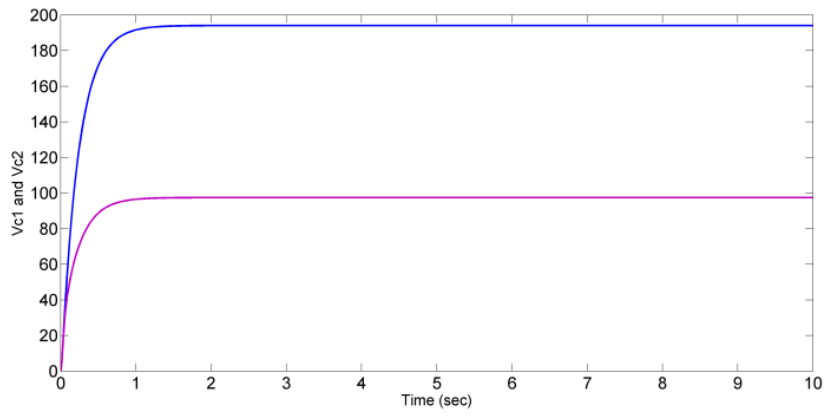

(a)

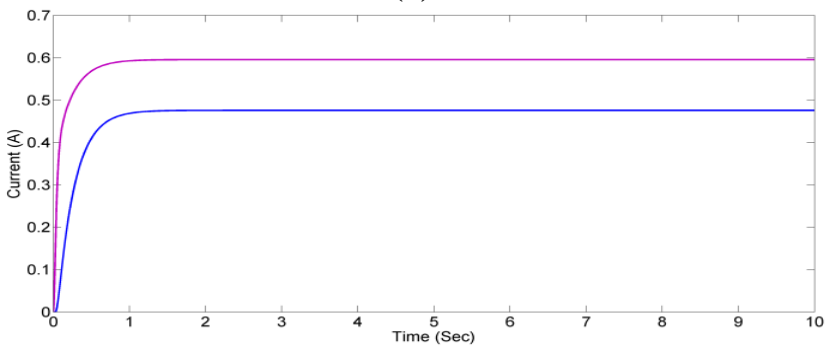

(b)

Published By:

Blue Eyes Intelligence Engineering \& Sciences Publication

(C) Copyright: All rights reserved. 


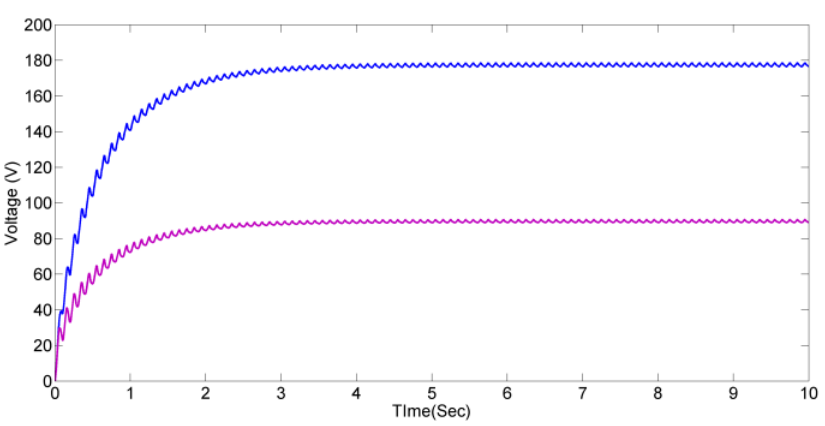

(c)

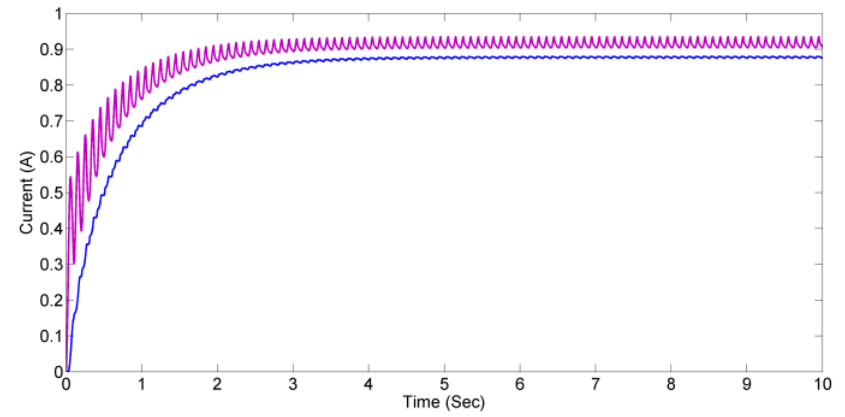

(d)

Fig.9. a)- d) Output Voltage and Current waveforms at different load conditions

Fig.9.a describes the output voltage $\mathrm{V}_{02}$ which is around $192 \mathrm{~V}$ for an input of $50 \mathrm{~V}$. Voltage across $\mathrm{C}_{\mathrm{M}}\left(\mathrm{V}_{01}\right)$ is $96 \mathrm{~V}$ which is exactly half of the load voltage. Fig.8.b. shows the load current $\mathrm{I}_{\mathrm{L}}$ and current due to voltage $\mathrm{V}_{01}$ at half load conditions. It shows the load current of $0.6 \mathrm{~A}$ and current of $0.45 \mathrm{~A}$ due to voltage $\mathrm{V}_{01}$ at half load is used across it. Fig.8.c shows the output voltage $\mathrm{V}_{02}$ of $165 \mathrm{~V}$ and capacitor Voltage $\mathrm{V}_{01}$ of $82 \mathrm{~V}$ at half load condition $(25 \Omega)$. Fig.8.d shows the current values at half load condition.

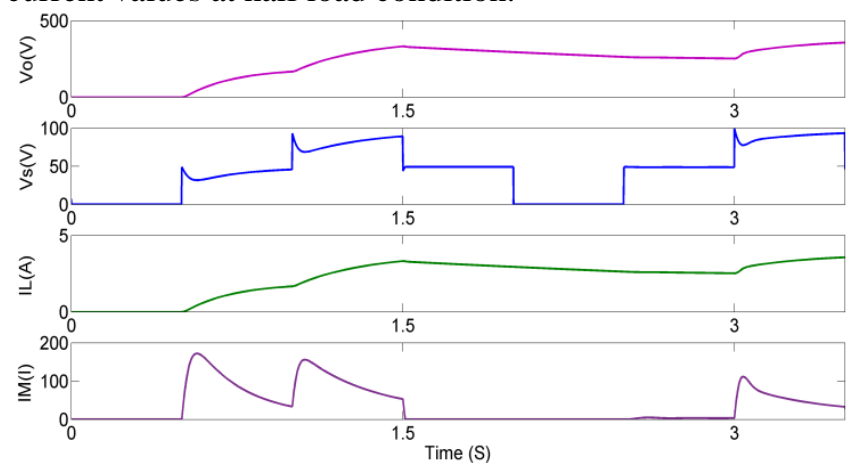

Fig.10 Performance parameters of proposed topology at various inputs

Simulation diagrams clearly describe that the output voltage $\mathrm{V}_{02}$ is twice as the capacitor voltage $\mathrm{V}_{01}$ as stated in (10) and (11). Fig.10 shows the performance parameters of proposed topology at different input conditions. Output voltage $V_{0}$ is decrease slightly when input increases from $V_{S}$ of $50 \mathrm{~V}$ to $2 \mathrm{~V}_{\mathrm{S}}$ of $100 \mathrm{~V}$. There is a sudden change in the output voltage due to charging and discharging of capacitors.

Inductor starts charging with change in input voltage and starts discharging. Load current decrease slightly when the input changes to zero. From the load current values, it is clearly known that the topology working in continuous conduction mode.

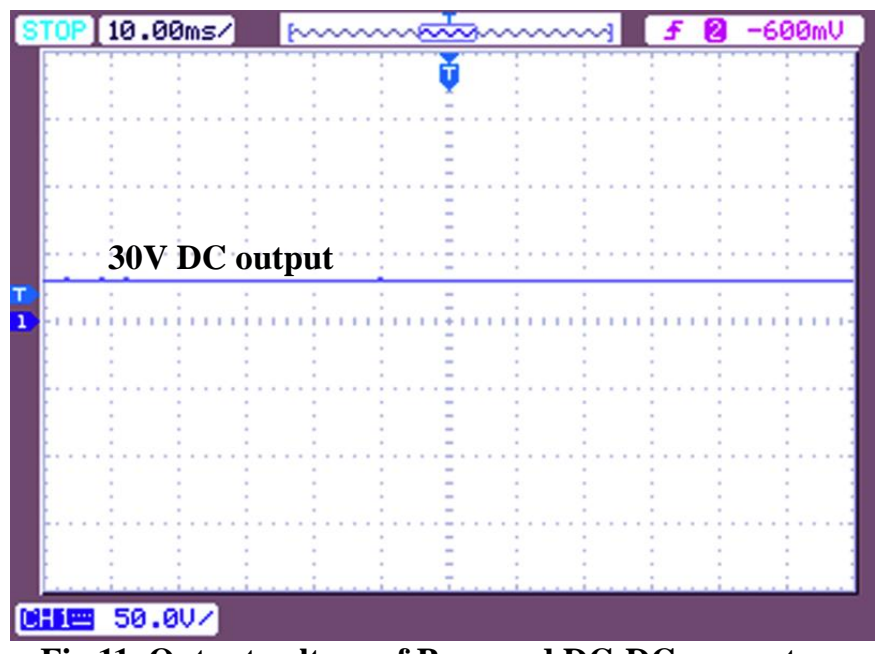

Fig.11. Output voltage of Proposed DC-DC converter

To evaluate the simulation results, hardware prototype has been developed and the output voltage is shown in Fig.11. An output voltage of $30 \mathrm{~V}$ is achieved for an input of $6 \mathrm{~V}$. Hardware use IRF840 Mosfet as switch. IC8951 is used to generate the gate pulses of Switches for switches $S_{1}$ and $S_{2}$. A PWM pulse of $10 \mathrm{KHz}$ is given to switch $S_{M}$. The parameters used in prototype are given in table 2 .

Table.2. Parameters used in Hardware Prototype

\begin{tabular}{|c|c|}
\hline Load & $25 \Omega$ \\
\hline Switch & IRF840 \\
\hline Controller & IC8951 \\
\hline Switching Frequency & $10 \mathrm{kHz}$ \\
\hline Input Voltage & $6 \mathrm{~V}$ (both inputs) \\
\hline Output Voltage & $30 \mathrm{~V}$ \\
\hline
\end{tabular}

Fig.12 shows the input waveforms and output voltage waveform. Inputs are given alternatively and it shows no decrement or change in the output voltage. The output voltage is maintained as constant at $30 \mathrm{~V}$ for the alternating inputs of $6 \mathrm{~V}$. From the simulation and experimental results, it is clearly shown that the the topology can produce constant output voltages for variable input voltages.

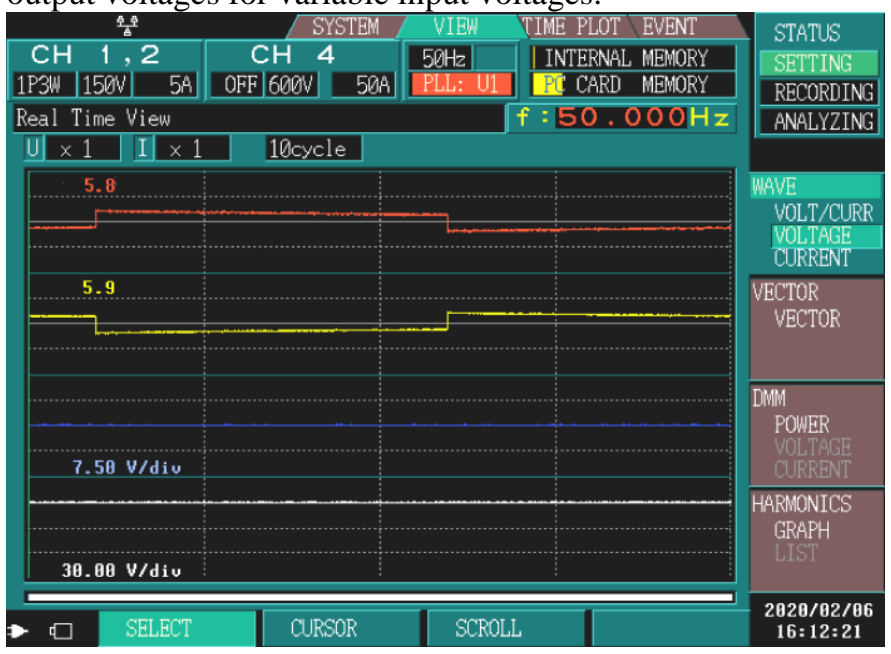

Fig.12. Input and output waveforms

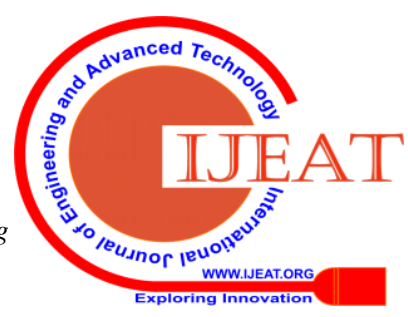




\section{CONCLUSION}

A novel multi-input and multi-output (MIMO) DC-DC converter was presented in this paper. The generalized structure and a dual input dual output topology also presented. This topology is suitable for hybrid power system uses renewable energy sources with variable output. Performance of the topology was discussed with analytical approach. This topology requires less number of inductor and switches to reduce the cost, volume and driver requirements. A detailed comparison with other topologies was also given. with Performance of the topology was verified using simulation and hardware prototype. The output was maintained constant with variable input voltages. By using closed loop control and MPPT techniques, the proposed topology can also be used for the hybrid systems with unequal input voltages.

\section{REFERENCES}

1. Hu, R., Zeng, J., Liu, J. and Yang, J., 'Double-input DC-DC converter for applications with wide-input-voltage-ranges', Journal of Power Electronics, 18(6), 2018,pp.1619-1626.

2. Fang Zheng Peng, 'A generalized multilevel inverter topology with self voltage balancing', , IEEE Transactions on Industry Applications, Volume 37, Issue 2, March-April 2001 pp.611 - 618

3. Shen, M., Peng, F.Z. and Tolbert, L.M., 'Multilevel DC-DC power conversion system with multiple DC sources', IEEE Transactions on Power Electronics, 23(1), 2008, pp.420-426.

4. Zhang, Fan, Fang Z. Peng, and Zhaoming Qian. 'Study of the multilevel converters in DC-DC applications.' 2004 IEEE 35th Annual Power Electronics Specialists Conference (IEEE Cat. No. 04CH37551),IEEE, vol. 2, 2004,pp. 1702-1706.

5. Nahavandi, A., Hagh, M.T., Sharifian, M.B.B. and Danyali, S., 'A nonisolated multiinput multioutput DC-DC boost converter for electric vehicle applications', IEEE Transactions on Power Electronics, 30(4), 2004,pp.1818-1835.

6. Dobbs, B.G. and Chapman, P.L., 'A multiple-input DC-DC converter topology', IEEE Power Electronics Letters, 1(1),2003, pp.6-9.

7. Shen, Miaosen, Fang Z. Peng, and Leon M. Tolbert. 'Multi-level dc/dc power conversion system with multiple dc sources.' 2007 IEEE Power Electronics Specialists Conference, IEEE, 2007, pp. 2008-2014..

8. Rosas-Caro, Julio C., Juan M. Ramirez, and Pedro Martín García-Vite. 'Novel DC-DC multilevel boost converter.' IEEE Power Electronics Specialists Conference, IEEE, 2008,pp. 2146-2151.

9. Khosrogorji, S., Ahmadian, M., Torkaman, H. and Soori, S., 'Multi-input DC/DC converters in connection with distributed generation units-A review', Renewable and Sustainable Energy Reviews, 66, 2016,pp.360-379.

10. Forouzesh, M., Siwakoti, Y.P., Gorji, S.A., Blaabjerg, F. and Lehman, B.,'Step-up DC-DC converters: a comprehensive review of voltage-boosting techniques, topologies, and applications', IEEE Transactions on Power Electronics, 32(12), 2017, pp.9143-9178.

11. Chen, J., Wang, C., Li, J., Jiang, C. and Duan, C.,'An Input-Parallel-Output-Series Multilevel Boost Converter With a Uniform Voltage-Balance Control Strategy', IEEE Journal of Emerging and Selected Topics in Power Electronics, 7(4),2019, pp.2147-2157.

12. Liao, Z., Lei, Y. and Pilawa-Podgurski, R.C. 'Analysis and design of a high power density flying-capacitor multilevel boost converter for high step-up conversion', IEEE Transactions on Power Electronics, 34(5), 2018, pp.4087-4099.

13. Bhaskar, M.S., Meraj, M., Iqbal, A. and Padmanaban, S., 'Nonisolated Symmetrical Interleaved Multilevel Boost Converter With Reduction in Voltage Rating of Capacitors for High-Voltage Microgrid Applications', 2019, IEEE Transactions on Industry Applications, 55(6), pp.7410-7424.

14. Rosas-Caro, J.C., Ramirez, J.M., Peng, F.Z. and Valderrabano, A., 'A DC-DC multilevel boost converter', IET Power Electronics, 3(1), 2010, pp.129-137.

15. Babaei, E. and Abbasi, O., 'Structure for multi-input multi-output dc-dc boost converter', 2016, IET Power Electronics, 9(1), pp.9-19.

16. Rezayi, S., Iman-Eini, H., Hamzeh, M., Bacha, S. and Farzamkia, S., 'Dual-output DC/DC boost converter for bipolar DC microgrids', IET Renewable Power Generation, 13(8),2019, pp.1402-1410.
17. Sundaramurthy, R, Sigamani, Titus, 'FITF-PDM: Unified controller design for non-isolated bidirectional DC-DC converter', International Transaction Electrcal Energ Syst., Vol.28, No.3, 2018.

18. M.Nandhini Gayathri, et.al., 'Performance Evaluation of Modified Cascaded Multilevel Inverter', Journal of Applied Sciences, 14,15, 2014, pp. $1750-1756$.

19. Keyhani, H., Toliyat, H.A.: 'A ZVS single-inductor multi-input multi-output dc-dc converter with the step up/down capability'. Proc ECCE, Denver, USA, 2013, pp. 5546-5552

20. Behjati, H., Davoudi, A.: 'Single-stage multi-port DC-DC converter topology', IET Power Electron., 2013, 6, (2), pp. 392-403

21. Jafari, M., Hunter, G., Zhu, J.: 'A new topology of multi-input multi-output buck-boost DC-DC converter for microgrid applications'. Proc. Power and Energy (PECon), Kota Kinabalu, Malaysia, 2012, pp. 286-291.

\section{AUTHORS PROFILE}

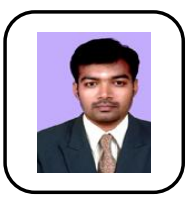

Ram Prakash Ponraj is currently working as Assistant Professor in Department of Electrical and Electronics Engineering in Saranathan College of Engineering, Tiruchirapalli, India. He is having more than ten years of teaching experience. He is the Life member of ISTE and MIE.

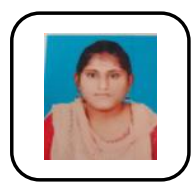

Devadharshini Ganeshprabhu is currently pursuing her Bachelor degree in Electrical and Electronics Engineering in Saranathan College of Engineering, Tiruchirapalli, India.

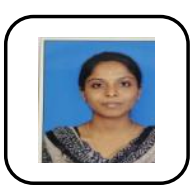

Haripriya Balaji is currently pursuing her Bachelor degree in Electrical and Electronics Engineering in Saranathan College of Engineering, Tiruchirapalli, India.

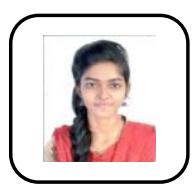

Hemadharshini Ganesan is currently pursuing her Bachelor degree in Electrical and Electronics Engineering in Saranathan College of Engineering, Tiruchirapalli, India

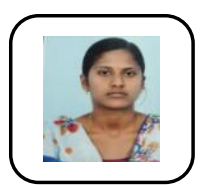

Keerthana Dhanabalan is currently pursuing he Bachelor degree in Electrical and Electronics Engineering in Saranathan College of Engineering, Tiruchirapalli, India

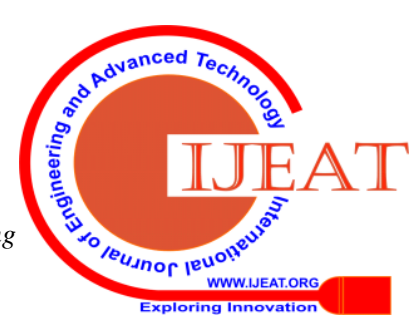

